\title{
As Relações de Trabalho e sua regulamentação no Brasil a partir da Revolução de $1930{ }^{1}$
}

Work relationship and its regulations in Brazil since the Revolution of 1930

Alex Faverzani da LUZ Janaína Rigo SANTIN ${ }^{\bullet}$

Resumo: Em virtude da Revolução ocorrida em 1930, a figura do Estado por intermédio das políticas de Getúlio Vargas, assume uma postura intervencionista compromissada com a questão social. Insere-se nessa perspectiva social o processo de regulamentação das relações de trabalho através da legislação, o qual ocasionava intensos debates e disputas entre a classe patronal, a classe trabalhadora e o Estado. A partir desse cenário, pretende-se desenvolver um estudo baseado nos direitos trabalhistas conquistados no decorrer da época, através das lutas e movimentos sociais realizados pela classe trabalhadora, o que de fato contribuiu em termos de pressão para que o Estado intermediasse os interesses das classes envolvidas. Para alcançar esse objetivo, a metodologia consistiu na pesquisa em obras bibliográficas relevantes para a temática, além de analisar os direitos e normas trabalhistas oriundos das Constituições promulgadas até então. Assim, busca-se elencar as trajetórias da regulamentação do trabalho no Brasil e demonstrar o papel fundamental do Estado no processo de desenvolvimento econômico do país, que por meio da normatização do trabalho buscava suprir os reflexos gerados pela forte crise econômica que se vivenciava nesse período.

Palavras-chave: Relações de trabalho; Regulamentação do trabalho; Revolução de 1930.

Abstract: Due to the Revolution occurred in 1930, the figure of the State through the policies of Getúlio Vargas, takes on an interventionist attitude committed to the social question. It is inserted, in this social perspective, the process of regulation of labor relationship through legislation, which resulted in intense debates and disputes between the employer class, the working class and the State. From this scenario on, we intend to develop a study based on labor rights achieved at the time, through the struggles and social movements by the working class, which really helped that the State, in terms of pressure, mediated the interests of the classes involved. To achieve this goal, the methodology was based on research in bibliographic works relevant to the thematics, and also analyzing the rights and labor standards coming from the constitutions enacted by then. Thus, it is attempted to rank the paths of labor regulation in Brazil and demonstrate the main role of the State in the economic development process of the country, and through the standardization of work it was aimed to overcome the reflections generated by the strong economic crisis that was being experienced during such time.

Keywords: Work relationship; Labor regulation; The Revolution of 1930.

\section{Considerações Iniciais}

Nas eleições de 1930, o candidato da oposição, Getúlio Vargas, é derrotado nas urnas. O resultado oficial, porém, foi acusado de fraudulento, o que não era novidade diante do sistema sufragista da República Velha. Em 3 de novembro de 1930, Getúlio Vargas assume a Presidência da República, por intermédio de um golpe de Estado, que também desencadeou no fim do regime da

\footnotetext{
- Mestrando - Programa de Pós-Graduação em História - Universidade de Passo Fundo - Rodovia BR 285, KM 171, CEP: 99001-970, Passo Fundo, RS, Brasil. Bolsista CAPES. E-mail: alexfaverzani@ terra.com.br

•• Professora Doutora - Faculdade de Direito e Programa de Pós-Graduação em História - Universidade de Passo Fundo - Rodovia BR 285, KM 171, CEP: 99001-970, Passo Fundo, RS, Brasil. Pós-Doutoranda em Direito pela Universidade de Lisboa, Portugal, com o auxílio financeiro da CAPES. E-mail: janainars@upf.br
} 
República Velha. A situação da época não era favorável em virtude dos reflexos da crise de 1929, assim, o Estado passa a dirigir o processo de industrialização e a coordenar politicamente os interesses distintos que se afirmavam ao longo desse processo, tudo como medida de resposta à crise provocada pela grande depressão. É dentro desse contexto que se criam condições para o surgimento do Direito do Trabalho, na forma de buscar a normatização das relações de trabalho oriundas do processo industrial.

A partir de então, o Governo de Getúlio Vargas além de preocupar-se em contornar a crise enfrentada, assume também o compromisso com a questão social do país. Dessa maneira, o direito do trabalho nasce como consequência da questão social que foi precedida da Revolução Industrial e da reação humanista que se propôs a garantir ou preservar a dignidade do ser humano ocupado no trabalho das indústrias.

Como se sabe, o trabalho tem por finalidade fazer com que o homem se empenhe para obter os bens necessários à sua subsistência, eis que dela depende seu bem maior, que é a vida. Esta, por sua vez, não subsiste sem os bens essenciais à existência humana se não por meio do trabalho, que há de ser honesto e digno, para que não atente contra os interesses maiores, não só de sua sobrevivência como da coletividade.

Logo, o direito do trabalho mostra-se eficaz como garantidor dos direitos sociais nas relações de trabalho da época e da atualidade brasileira, capaz de exigir a intervenção do Estado na sociedade e no mercado a fim de reduzir as desigualdades sociais e promover a justiça social em prol do Estado Democrático de Direito.

\section{A regulamentação do trabalho e sua positivação nas Constituições}

Com a Revolução de 1930 surge o desafio de o Brasil sair da predominância de uma economia agrária para inserir-se numa sociedade industrializada, marcada de um lado, pela aparição de relações de trabalho com maior grau de complexidade e desenvolvimento, e de outro, pela concretização da regulação do trabalho como instituto jurídico. Através deste marco histórico o país vivencia um período classificado como "Estado intervencionista", apesar de ser dotado de natureza autoritária, não transparecendo como "Estado de bem-estar social", que por ora viria regulamentar a denominada “questão social”. (VECCHI, 2009, p. 46).

Logo de início no poder, no mesmo ano de sua posse, por intermédio de Decreto $\mathrm{n}^{\circ} 19.433$ de 26 de novembro de 1930, Getúlio Vargas cria o Ministério do Trabalho, Indústria e Comércio. (NASCIMENTO, 2003, p. 72). Meses após, em 4 de fevereiro de 1931, institui-se o Departamento Nacional do Trabalho (DNT) pelo Decreto nº 19.671-A. (DELGADO, 2001, p. 59). Magda Barros Biavaschi (2007, p. 87) justifica que a criação do Ministério do Trabalho tinha como finalidade "superintender a questão social, o amparo e a defesa do operariado urbano e rural". Aduz ainda, que 
A partir desse momento o Brasil passaria a lutar pela superação das características que, até então, marcavam sua estrutura econômica, social e política: os resquícios de uma ordem escravocrata, patriarcal e monocultora herdada dos tempos coloniais; uma sociedade eminentemente agrária; uma economia subordinada a um modelo primário exportador; um operariado urbano esparso e não organizado; uma política "café com leite", com domínio dos proprietários rurais do eixo Minas/São Paulo; o sufrágio não universal e não secreto, sem participação feminina; a Questão Social, tratada genericamente como questão de polícia. (BIAVASCHI, 2007, p.88).

A Constituição de 16 de julho de 1934, originária do Governo Provisório, trouxe consigo a característica de pioneirismo na introdução de princípios sobre a ordem econômica e social, dentre eles os relativos à família, à educação e cultura, ao funcionalismo público, além daqueles destinados ao trabalho como

salário mínimo, jornada de oito horas, proteção ao trabalho aos menores de 14 anos, férias anuais remuneradas, indenização ao trabalhador despedido e assistência médica e sanitária ao trabalhador. Outros pontos importantes foram a criação da representação profissional na Câmara dos Deputados [...], a afirmação do princípio da pluralidade e da autonomia sindical [...] e a criação da Justiça do Trabalho, à qual, entretanto, não se aplicariam as disposições pertinentes ao Poder Judiciário. (GALVÃO, 1981, p. 68-69).

Porém, Delgado (2001, p. 58-59) menciona que com o advento da Carta de 1934, ensejou-se em maior liberdade e autonomia sindical, ou seja, "a própria pluralidade sindical foi acolhida por esta Constituição”. Diz ainda, que após essa percepção por parte do governo federal foi retomado o controle pleno sobre as ações trabalhistas, através do estado de sítio de 1935, "dirigido preferencialmente às lideranças políticas e operárias adversárias da gestão oficial”. Com isso, possibilitou-se ao governo federal que eliminasse qualquer foco de resistência à sua estratégia político-jurídica, "firmando solidamente a larga estrutura do modelo justrabalhista, cujas bases iniciara logo após o movimento de outubro de 1930”.

Diante disso, com a justificativa de que a Revolução de 30 é desviada de seus rumos pela influência dos velhos costumes políticos oligárquicos, instaura-se a ditadura Vargas, juntamente com a outorga da Constituição de 1937. Nela, aprofundou-se o modelo sindical oficial corporativista, onde “a essa altura já se tornara juridicamente explícito o que fora prática institucional desde 1935: a inviabilidade de coexistência de qualquer outro sindicato com o sindicalismo oficial”. (DELGADO, 2001, p. 59).

Ferrari; Nascimento e Martins Filho (1998, p. 56-57) ilustram as principais inovações trazidas pela Constituição de 1937

A Constituição, de 10.11.1937, sob a justificativa de que o Estado, sob as instituições existentes, não dispunha de meios normais de preservação e de defesa da paz, da segurança e do bem-estar do povo, e, com o apoio das Forças Armadas e cedendo às inspirações da opinião nacional, foi editada pelo então Presidente da República Getúlio Vargas, cujo Ministro da Justiça era o jurista Francisco Campos. Era o Estado Novo, nitidamente intervencionista, principalmente na 
Ordem Econômica e Social. A greve foi proibida, por ser nociva à produção e, portanto, antissocial. O Sindicato passou a ser assistencial com funções delegadas até para impor contribuições a seus filiados, publicizando-se. Fixou-se o princípio do sindicato único, com a reserva legal de que só o Estado poderia reconhecer-lhe a legitimidade, mediante Carta Sindical. Criou-se o Conselho da Economia Nacional (art. 57), com representantes de vários ramos da produção nacional, garantida a igualdade de representação entre empregadores e empregados, conforme cinco seções: 1) da indústria e do artesanato; 2) da agricultura; 3) do comércio; 4) dos transportes; e 5) do crédito.

$\mathrm{O}$ elenco dos direitos sociais permanece basicamente o mesmo, exceto nas alterações no conceito de trabalho - visto como dever social, notadamente pela influência exercida da Carta Del Lavoro da Itália fascista. Contudo, marca "um retrocesso à liberdade sindical, à medida que os sindicatos foram encarados como exercentes de funções delegadas do Poder Público". (ARRUDA, 1998, p. 33).

Para confirmar as alegações de Arruda acima transcritas, em consonância Nascimento (2003, p. 73) afirma que conforme observância dos historiadores,

o art. 138 da norma constitucional de 1937 é a transcrição da cláusula III da Carta Del Lavoro: "A associação profissional ou sindical é livre. Porém, apenas o sindicato regularmente reconhecido pelo Estado tem o direito de representar legalmente os que participarem da categoria de produção para que foi constituído, de defender-lhes os direitos perante o Estado e as outras associações profissionais, de estipular contratos coletivos de trabalho obrigatórios para todos os seus associados, de impor-lhes contribuições e de exercer, em relação a eles, funções delegadas de poder público".

Nascimento, procedendo à análise crítica, salienta que

segundo as ideias que inspiraram o corporativismo italiano, os sindicatos deviam permanecer sob o controle do Estado; exerciam, como a lei declara, funções originariamente da competência do Estado, por este transferidas às organizações sindicais que, assim, deviam ser entendidas como uma parcela do próprio Estado e não como entidades de direito privado com autonomia para a própria organização e desenvolvimento das suas atividades. (NASCIMENTO, 2003, p. 73-74).

Acerca das novidades trazidas pela Constituição de 1937, se faz necessário frisar o especial destaque de Arruda (1998, p. 33), a qual enfatiza que "foi sob a vigência da Constituição de 1937 que houve a instalação da Justiça do Trabalho, ainda no âmbito do Ministério do Trabalho e não do Poder Judiciário, em data de $1^{\circ}$ de maio de 1941”. Entretanto, no dizer de Galvão (1981, p. 70), “a grande obra do chamado Estado Novo no campo social, foi a promulgação da Consolidação das Leis do Trabalho em 1943".

Apesar das aparentes conquistas sociais, a Constituição de 1937 é duramente criticada pelos constitucionalistas da época - entendem eles que são aplicados somente naqueles dispositivos mais úteis e necessários ao Governo, com vistas a instalar o arbítrio do executivo. Com isso, o seu texto não é aplicado em sua totalidade. 
Na sequência histórica, mais precisamente em 18 de setembro de 1946, foi promulgada a nova Constituição, votada por Assembleia Constituinte legalmente convocada, buscou reorganizar o país nos moldes democráticos, onde incluiu a Justiça do Trabalho como órgão do Poder Judiciário, e ainda,

\begin{abstract}
No título reservado à Ordem Econômica e Social, está dito que ela deve ser organizada conforme os princípios da justiça social, conciliando a liberdade de iniciativa com a valorização do trabalho humano. A todos deve ser assegurado trabalho que possibilite existência digna, e o trabalho continuou sendo obrigação social, neste passo entendida a parêmia como sendo uma necessidade social pelo que dele é gerado em termos de reflexos positivos para toda a sociedade. $\mathrm{O}$ artigo 157 trata da legislação do trabalho e da previdência social, praticamente repetindo o que anteriormente existia, tanto na Constituição de 34, como na de 37, porém acrescentando: estabilidade ao trabalhador rural; assistência aos desempregados; obrigatoriedade de seguro pelo empregador contra acidentes do trabalho; reconhecimento do direito de greve; fixação de percentagens de empregados brasileiros nos serviços públicos dados em concessão e nos estabelecimentos de determinados ramos do comércio e da indústria; e a participação nos lucros. (FERRARI; NASCIMENTO; MARTINS FILHO, 1998, p. 59).
\end{abstract}

A Constituição de 1967 foi promulgada no período em que o Brasil se encontrava sob o regime militar instaurado com a Revolução de 1964, "para combater a inflação que atingia limites alarmantes e para prevenir o País do comando da esquerda política que crescia a olhos vistos”. A justificativa maior de sua promulgação foi a de garantir a harmonia e a solidariedade entre os fatores da produção, bem como a valorização do trabalho humano. No campo das inovações

praticamente, manteve os direitos dos trabalhadores, individuais e coletivos, da $\mathrm{CF} / 46$, restringindo, porém, o direito à greve, proibindo-a nas atividades essenciais e nos serviços públicos. Enfatizou-se a integração do trabalhador na vida e no desenvolvimento da empresa, com participação nos lucros e, excepcionalmente, na gestão da empresa. Dessa inovação surgiu o PIS, depois o PASEP, e, posteriormente, a união dos dois, um gerido pela Caixa Econômica Federal e, o segundo, pelo Banco do Brasil. A idade mínima para o trabalho passou a ser de 12 anos, contrariando, inclusive, recomendações internacionais. A principal alteração, quanto ao trabalho, foi sem dúvida, a introdução do FGTS, em substituição, ao menos parcial, do direito à indenização, que, somente com $\mathrm{CF} / 88$, teve seu golpe de morte finalmente dado. (FERRARI; NASCIMENTO; MARTINS FILHO, 1998, p. 59-60).

Alguns autores, em especial Lacerda (2000, p. 65), sustentam que o golpe militar de 1964 e a outorga da Constituição de 1967 derrubaram a ordem social mantida em face da Constituição de 1946 e “o Brasil passou a experimentar um retrocesso institucional”. No plano dos Direitos Sociais, os trabalhadores perderam mais uma vez. "A política reacionária imprimida pelo golpe de Estado desabou sobre o sistema brasileiro, mormente sobre a área social, colocando um freio na luta por melhores condições de sobrevivência”. 
Apesar da ditadura e da derrocada das liberdades individuais, as greves são acontecimentos constantes no decorrer do ano de 1979, que se firma como um marco de relevância na luta sindical. Na opinião de Lacerda,

pode-se afirmar que esse avanço do movimento sindical brasileiro foi o prenúncio da rearticulação da sociedade civil, [...] sufocada por uma das ditaduras mais cruéis das que se instalaram na América Latina, ainda que os historiadores burgueses queiram dizer o contrário, ou destacar uma época de suposto 'milagre econômico', a sociedade civil brasileira voltou a organizar-se nos anos 80. (LACERDA, 2000, p. 76).

E continua: "a partir da primeira eleição direta para Governador, em 1982, o povo brasileiro toma as ruas do país [...] essa eleição teve um efeito pedagógico sobre a sociedade brasileira, exercitando-a no sentido da importância e da necessidade da democracia”. Esse episódio é identificado como a campanha pelas "Diretas Já". Após, com o governo de José Sarney, vicepresidente de Tancredo Neves - impossibilitado de assumir o cargo - dá-se início à "Nova República", que assume o compromisso de "resgatar a enorme dívida social contraída pela ditadura”, e de redemocratizar o país. (LACERDA, 2000, p. 74-75).

Diante de tal situação, configura-se a possibilidade da realização de uma nova Assembleia Constituinte, ocorrida em $1^{\circ}$ de fevereiro de 1987 , ensejando na promulgação da Constituição de 1988. Ferrari; Nascimento; Martins Filho (1998, p. 101) ratifica que "a instalação da Assembleia Nacional constituinte foi um acontecimento significativo como avanço na reforma política e jurídica do País, com reflexos diretos na ordem econômica e social e na regulamentação do trabalho".

A Constituição de 1988 trouxe profundas mudanças no campo do direito do trabalho, Delgado (2008) as descreve da seguinte forma:

Ao lado de todos esses aspectos apontados, a Constituição de 5.10 .1988 emergiu, também, como a mais significativa Carta de Direitos já escrita na história jurídicopolítica do país. Não se conduziu, porém, a nova Constituição pela matriz individualista preponderante em outras Cartas Constitucionais não autocráticas (como a de 1946). Nessa linha, superou a equívoca dissociação (propiciada pela Carta de 46) entre liberdade e igualdade, direitos individuais e direitos coletivos ou sociais. A nova Constituição firmou largo espectro de direitos individuais, cotejados a uma visão e normatização que não perdem a relevância do nível social e coletivo em que grande parte das questões individuais deve ser proposta. Nesse contexto é que ganhou coerência a inscrição que produziu de diversificado painel de direitos sociotrabalhistas, ampliando garantias já existentes na ordem jurídica, a par de criar novas no espectro normativo dominante. Na linha isonômica, que é sua marca pronunciada, igualizou direitos entre empregados urbanos e rurais (art. $7^{\circ}$, caput, $\mathrm{CF} / 88$ ), estendendo a mesma conduta aos trabalhadores avulsos (art. $7^{\circ}$, XXXIV). De par disso, avançou, significativamente, o rol de direitos cabíveis à categoria empregatícia doméstica (parágrafo único, art. $7^{\circ}, \mathrm{CF} / 88$ ). Ampliou as proteções jurídicas à empregada gestante, seja através do mais largo prazo de licença previdenciária - 120 dias (art. $7^{\circ} \mathrm{XVIII}, \mathrm{CF} / 88$ ), seja através da garantia de emprego instituída, com prazo até cinco meses após o nascimento (art. 10, II, "b", ADCT, CF/88). Ao lado disso, ampliou de um para cinco dias a interrupção do contrato de trabalho para o pai, no período de nascimento do filho (art. $7^{\circ}$, XIX, e 
art. 10, $\S 1^{\circ}$, ADCT, combinados com art. 473, III, CLT). Supriu, ainda, o aviso prévio de oito dias (art. 487, I, CLT), ampliando o prazo para trinta dias (art. $7^{\circ}$, XXI, CF/88). Também estendeu para cinco anos o prazo bienal de prescrição do art. 11, CLT, mitigando os efeitos derruidores do antigo preceito celetista excessivamente restritivo (art. $7^{\circ}$, XXIX, "a", CF/88). Na temática da extinção do contrato de emprego, a Carta de 1988 caracterizou-se, contudo, por certa perplexidade, não firmando conduta definitiva sobre o tema. Estendeu o FGTS, como visto, a todo empregado (art. $7^{\circ}$, III, CF/88), ampliando o acréscimo rescisório (art. 10, I, CF/88: fala-se em "multa fundiária") e minorando, desse modo, os efeitos negativos da dispensa para o empregado. Mas, em contrapartida, extinguiu a velha indenização celetista (art. $7^{\circ}$, I, CF/88; art. 447, caput, CLT), remetendo à legislação complementar a fixação de indenização compensatória. (DELGADO, 2008, p. 126-127).

Em suma, Ferrari; Nascimento; Martins Filho (1998, p. 117) concluem que as modificações trazidas com a nova Constituição possibilitaram melhores condições para o desenvolvimento do país, porém, não a plena realização, do princípio da liberdade sindical.

Vecchi (2009, p. 46) faz um breve relato que resume a trajetória da regulamentação do direito trabalhista à luz das Constituições após o período revolucionário de 1930, apontando que a Constituição de 1934 foi concebida como a primeira Constituição social do país, apesar de não ter verdadeira implementação prática; já a Constituição de 1937, bem como a Constituição de 1946, "marcam momentos de forte intervenção estatal no mundo do trabalho". Ressalta ainda, que é após esse período "que se ergue toda a ossatura legislativa brasileira sobre o trabalho", permanecendo em quase sua totalidade sem modificações textuais, apesar da presença do golpe militar de 1964, as Constituições de 1967 e a emenda Constitucional de 1969 “(exceto se faça, principalmente, à Lei do FGTS, que liquidou com a estabilidade no emprego do setor privado, primeira experiência flexibilizante da América Latina)", até então, à presente Constituição de 1988.

\section{A Consolidação das Leis do Trabalho de 1943 (CLT)}

Além da positivação de leis trabalhistas nas Constituições ao longo da história, haviam inúmeras legislações esparsas que também eram editadas na época, com o intuito de trazer complementos às já existentes. No entanto, notava-se um crescimento de forma desordenada dessas leis esparsas, especificamente pelo fato de que cada profissão possuía uma norma específica para aplicação. Em virtude de tal situação, o Governo optou por reunir todos os textos legais num só diploma, entretanto, foi mais além de uma simples compilação, pois embora denominada “Consolidação", a publicação apresentou inovações, aproximando-se de um verdadeiro Código. Nesta unificação foram reunidas as leis sobre "o direito individual do trabalho, o direito coletivo do trabalho e o direito processual do trabalho". O que originou a então "Consolidação das Leis do Trabalho - CLT", promulgada pelo Decreto-lei $n^{\circ} 5.452$, de $1^{\circ}$ de maio de 1943. (NASCIMENTO, 2003, p. 75-76). 
Acerca da edição da Consolidação das Leis do Trabalho, Ferrari; Nascimento; Martins Filho (1998, p. 95) comentam que foi um “[...] meio de aperfeiçoamento do sistema legal sobre as relações coletivas de trabalho, que em nada contribuiu, não passando de mera reunião de textos já existentes com algumas pinceladas pouco ou em quase nada inovadoras".

A partir dos posicionamentos de Nascimento (2003) e Ferrari; Nascimento; Martins Filho (1998), em relação à promulgação da Consolidação das Leis do Trabalho, pode-se considerar que contribuiu no aspecto de organização das legislações esparsas, de forma a concentrá-las em um único volume jurídico, a fim de facilitar possíveis consultas.

Biavaschi (2007, p. 119-121) ilustra as novidades trazidas pela CLT em dois institutos básicos: a) “a despersonalização da figura do empregador” que ensejou na adoção da teoria contratualista para a CLT; b) "o contrato-realidade" que inspirou na redação do art. 442 da CLT, o qual estabelece que "o contrato individual de trabalho é o acordo tácito ou expresso correspondente à relação de emprego".

Em 1955 foi instituída uma comissão de revisão da CLT, porém sem resultados. Em 1961, através da Portaria ${ }^{\circ}$ 482-B do Ministério da Justiça, foram designados os juristas Evaristo de Moraes Filho e Mozart Victor Russomano para a elaboração de anteprojetos do Código de Trabalho e do Código de Processo do Trabalho, também sem sucesso, apesar de concluídos os estudos e remetidas as propostas ao Poder Executivo pelos elaboradores. (NASCIMENTO, 2003, p. 77-78).

\section{Leis esparsas trabalhistas (1930-1943)}

No período posterior à Revolução de 1930, o direito do trabalho passava por um processo de formação com base nas relações de trabalho que emergiam no decorrer da evolução industrial, assim, inúmeras leis eram criadas com finalidade de regular tais relações de trabalho, na perspectiva de garantir medidas assecuratórias à classe operária.

Biavaschi (2007, p. 205-220) em sua obra, apresenta um esboço de todas as leis esparsas promulgadas, mais especificamente do lapso temporal compreendido entre 1930 a 1943, período este que antecede à Consolidação das Leis do Trabalho (CLT), promulgada em 1943, a qual buscou reunir toda esta legislação esparsa e demais acréscimos legais atinentes à normatização das relações de trabalho. 


\begin{tabular}{|c|c|}
\hline \multicolumn{2}{|c|}{ Leis Esparsas - $(1930-1943)$} \\
\hline Decreto $19.398,11$ de setembro de 1930 & $\begin{array}{l}\text { Instituiu o Governo Provisório da República dos Estados Unidos do } \\
\text { Brasil }\end{array}$ \\
\hline Decreto $19.433,26$ de novembro de 1930 & Criou o Ministério do Trabalho, Indústria e Comércio \\
\hline Decreto $19.482,12$ de dezembro de 1930 & $\begin{array}{l}\text { Limitou a entrada no território nacional de passageiros de terceira } \\
\text { classe; dispôs sobre localização e amparo de trabalhadores nacionais e } \\
\text { deu outras providências }\end{array}$ \\
\hline Decreto $20.303,19$ de agosto de 1931 & Nacionalização do trabalho: marinha mercante \\
\hline Decreto $19.667,4$ de fevereiro de 1931 & Criou o Departamento Nacional do Trabalho \\
\hline Decreto $19.770,19$ de março de 1931 & Criou a Organização Sindical, institui o sindicato único. \\
\hline Decreto $21.175,21$ de março de 1932 & Instituiu a Carteira de Trabalho \\
\hline Decreto $21.186,22$ de março de 1932 & Regulou o horário de trabalho no comércio em 8 horas diárias ou 48 semanais \\
\hline Decreto $23.322,3$ de novembro de 1933 & $\begin{array}{l}\text { Definiu o horário de trabalho em bancos e casas bancárias em } 6 \text { horas } \\
\text { diárias e } 36 \text { semanais }\end{array}$ \\
\hline Decreto $24.634,10$ de julho de 1934 & Estabeleceu o horário de trabalho nos serviços de telegrafia \\
\hline Decreto $21.364,4$ de maio de 1932 & Regulamentou o horário de trabalho na indústria \\
\hline Decreto 21.417-A, 17 de maio de 1932 & Trabalho da mulher: na indústria e no comércio \\
\hline Decreto $22.042,3$ de novembro de 1932 & Trabalho do menor \\
\hline Decreto $21.761,23$ de agosto de 1932 & Convenção coletiva de trabalho \\
\hline Decreto $21.396,12$ de maio de 1932 & Comissões mistas de conciliação - Jurisdição Paritária \\
\hline Decreto $22.132,25$ de novembro de 1932 & Juntas de Conciliação e Julgamento - Jurisdição Paritária \\
\hline Decreto $21.690,1^{\circ}$ de agosto de 1932 & Inspetorias Regionais do Ministério do Trabalho, Indústria e Comércio \\
\hline Decreto $22.131,23$ de novembro de 1932 & Multas e recursos \\
\hline Decreto $23.259,20$ de outubro de 1933 & Jurisdição Administrativa - institui delegacias de trabalho marítimo \\
\hline Decreto $24.784,14$ de julho de 1934 & Jurisdição Administrativa - novo regulamento do CNT \\
\hline Decreto $24.637,10$ de julho de 1934 & Lei de Acidentes do Trabalho \\
\hline Lei $n^{\circ} 62,5$ de junho de 1935 & Lei da despedida \\
\hline Lei 185,14 de janeiro de 1936 & Institui as Comissões de Salário Mínimo \\
\hline Decreto 279,7 de agosto de 1935 & Empregados no serviço ferroviário \\
\hline Lei 264,5 de outubro de 1936 & Empregados nos serviços públicos \\
\hline Lei 228,24 de julho de 1936 & Empregados em hotéis \\
\hline Lei 435, 17 de maio de 1937 & Grupos industriais e solidariedade \\
\hline Decreto $1.361,12$ de janeiro de 1937 & Moléstias profissionais \\
\hline Decreto-lei 39, 3 de dezembro de 1937 & Competência do juízo Cível - cumprimento das decisões \\
\hline Decreto-lei 1.237, 2 de maio de 1939 & Organiza a Justiça do Trabalho \\
\hline Decreto-lei $1.346,15$ de junho de 1939 & Reorganiza o Conselho Nacional do Trabalho \\
\hline Decreto $6.596,12$ de dezembro de 1940 & Regulamento da Justiça do Trabalho \\
\hline Decreto-lei 3.229, 30 de abril de 1941 & Processos pendentes \\
\hline Decreto-lei 4.037, 19 de janeiro de 1942 & $\begin{array}{l}\text { Atribui natureza social aos arts. } 81 \text { do Código Comercial e } 1.221 \text { do } \\
\text { Código Civil }\end{array}$ \\
\hline
\end{tabular}


Nota-se o constante aperfeiçoamento do processo de regulamentação das relações de trabalho, o mesmo ampliava-se na medida em que surgiam novos postos de trabalho, resultando na edição de novas leis trabalhistas.

\section{Considerações Finais}

No decorrer do presente trabalho evidenciou-se a trajetória histórica do sistema normativo das relações de trabalho do período sucessor à Revolução de 1930. No entanto, em tempos atuais, o direito do trabalho conta além da Consolidação das Leis do Trabalho (CLT), também com a Constituição Federal de 1988, em especial em seu art. $7^{\circ}$, nos seus vários incisos, onde trata do trabalho sob regime de emprego, pelo fato de esta ter sido a maior preocupação do legislador no momento em que analisa o trabalho, sob o aspecto em que o trabalhador empresta seu esforço físico, ou intelectual, ao poder econômico, devendo haver, nessa desigualdade de forças, um equilíbrio de ordem legal.

Acredita-se que este olhar sobre o trabalho deve ser ampliado, ou seja, além das relações de emprego com suas respectivas garantias, no sentido de que toda espécie de trabalho merece tratamento jurídico adequado, pois está em jogo o direito ao trabalho, muito mais do que o direito do trabalho em si, o qual só ampara legalmente aquele que possui vínculo empregatício.

Todo esse trabalho, classificado como informal por não estar enquadrado no formalismo do contrato empregatício, terá que ter proteção legal e terá que ser chamado ao convívio dos que contribuem para a Previdência Social e para o Imposto de Renda, a fim de que não só empregados e servidores públicos o façam, de forma muito mais penosa do que deveria. Há a efetiva necessidade da concretização desse chamamento sob pena da não constatação dos valores sociais existentes nessas modalidades de trabalho, que em nada contribuirão para a sociedade, nem para si próprios, em termos de futuro.

Portanto, o Direito do Trabalho deve se posicionar além do campo em que está inserido, na perspectiva de zelar pelo direito à sobrevivência, o maior bem da vida, e para que se revista dos valores sociais inerentes a toda e qualquer pessoa humana.

\section{Referências Bibliográficas}

ARRUDA, Kátia Magalhães. Direito Constitucional do Trabalho. São Paulo: LTr Editora, 1998.

BIAVASCHI, Magda Barros. O Direito do Trabalho no Brasil 1930 - 1942: A Construção do Sujeito de Direitos Trabalhistas. São Paulo: LTr: Jutra - Associação Luso-Brasileira de Juristas do Trabalho, 2007. 
DELGADO, Mauricio Godinho. Introdução ao Direito do Trabalho. São Paulo, LTr Editora, 2001, $3^{\mathrm{a}}$ ed.

Curso de Direito do Trabalho. São Paulo: LTr Editora, 2008, $7^{\mathrm{a}}$ ed.

FERRARI, Irany; NASCIMENTO, Amauri Mascaro; MARTINS FILHO, Ives Gandra da Silva. História do Trabalho, do Direito do Trabalho e da Justiça do Trabalho. São Paulo, LTr Editora, 1998.

GALVÃO, Paulo Braga. Os Direitos Sociais nas Constituições. São Paulo: LTr, 1981.

LACERDA, Antônia Denise. Cidadania, Participação e Exclusão. Itajaí, Univali, 2000, v. 1.

NASCIMENTO, Amauri Mascaro. Curso de Direito do Trabalho: história e teoria geral do direito: relações individuais e coletivas do trabalho. São Paulo: Saraiva, 2003, 18 ed. rev. e atual.

VECCHI, Ipojucan Demétrius. Noções de Direito do Trabalho: um enfoque constitucional. Passo Fundo, UPF Editora, 2009, $3^{\text {a }}$ ed.

WOLKMER, Antônio Carlos. Constitucionalismo e Direitos Sociais no Brasil. São Paulo: Acadêmica, 1989.

\section{NOTAS}

${ }^{1}$ Trabalho aprovado e apresentado no IV Congresso Internacional de História, promovido pela Universidade Estadual de Maringá.

Artigo recebido em 05/2010. Aprovado em 09/2010. 